\title{
Spotlight on esophageal perforation: A multinational study using the Pittsburgh esophageal perforation severity scoring system
}

\author{
Michael Schweigert, MD, PhD, ${ }^{a}$ Hugo Santos Sousa, MD, ${ }^{b}$ Norbert Solymosi, PhD, ${ }^{c}$ \\ Aleksandar Yankulov, MD, ${ }^{\mathrm{d}}$ Marta Jiménez Fernández, MD, ${ }^{\mathrm{e}}$ Rory Beattie, $\mathrm{MD},{ }^{\mathrm{f}}$ Attila Dubecz, MD, PhD, ${ }^{\mathrm{g}}$ \\ Charlotte Rabl, MD, PhD, ${ }^{\mathrm{h}}$ Simon Law, MD, PhD, ${ }^{\mathrm{i}}$ Daniel Tong, MD, ${ }^{\mathrm{j}}$ Danail Petrov, MD, ${ }^{\mathrm{k}}$ \\ Annemaria Schäbitz, MD, ${ }^{\mathrm{a}}$ Rudolf J. Stadlhuber, MD, ${ }_{\mathrm{h}}$ Julia Gumpp, MD, ${ }^{\mathrm{k}}$ Dietmar Ofner, MD, PhD, ${ }^{\mathrm{h}}$ \\ Jim McGuigan, MD, ${ }^{\mathrm{f}}$ José Costa-Maia, MD, PhD, FACS, ${ }^{\mathrm{b}}$ Helmut Witzigmann, MD, PhD, ${ }^{\mathrm{a}}$ and \\ Hubert J. Stein, MD, PhD, FACS ${ }^{g}$
}

\begin{abstract}
Objective: The Pittsburgh group has suggested a perforation severity score (PSS) for better decision making in the management of esophageal perforation. Our study aim was to determine whether the PSS can be used to stratify patients with esophageal perforation into distinct subgroups with differential outcomes in an independent study population.

Methods: In a retrospective study cases of esophageal perforation were collected (study-period, 1990-2014). The PSS was analyzed using logistic regression as a continuous variable and stratified into low, intermediate, and high score groups.

Results: Data for 288 patients (mean age, 59.9 years) presenting with esophageal perforation (during the period 1990-2014) were abstracted. Etiology was spontaneous (Boerhaave; $\mathrm{n}=119$ ), iatrogenic (instrumentation; $\mathrm{n}=85$ ), and traumatic perforation $(n=84)$. Forty-three patients had coexisting esophageal cancer. The mean PSS was 5.82, and was significantly higher in patients with fatal outcome (n $=57 ; 19.8 \%$; mean PSS, 9.79 vs $4.84 ; P<.001)$. Mean PSS was also significantly higher in patients receiving operative management $(\mathrm{n}=200$; $69 \%$; mean PSS, 6.44 vs $4.40 ; P<.001)$. Using the Pittsburgh strata, patients were assigned to low PSS $(\leq 2 ; \mathrm{n}=63)$, intermediate PSS $(3-5 ; \mathrm{n}=86)$, and high PSS $(>5 ; \mathrm{n}=120)$ groups. Perforation-related morbidity, length of stay, frequency of operative treatment, and mortality increased with increasing PSS strata. Patients with high PSS were 3.37 times more likely to have operative management compared with low PSS.
\end{abstract}

Conclusions: The Pittsburgh PSS reliably reflects the seriousness of esophageal perforation and stratifies patients into low-, intermediate-, and high-risk groups with differential morbidity and mortality outcomes. (J Thorac Cardiovasc Surg 2016;151:1002-11)

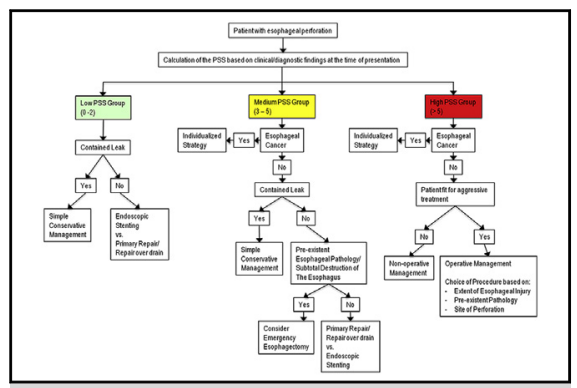

Management of esophageal perforation based on the Pittsburgh perforation severity score (PSS).

\section{Central Message}

The PSS measures the severity of esophageal injury and can be used to stratify patients into low-, intermediate-, and high-risk groups.

\section{Perspective}

Treatment of esophageal perforation is a challenging task. The Pittsburgh perforation severity scoring system stratifies patients into low-, intermediate-, and high-risk groups with differential morbidity and mortality outcomes. A prospective database is needed to further analyze whether the score has influence on treatment and can identify appropriate candidates for nonoperative management.

See Editorial Commentary page 1012.
Esophageal perforation is a devastating condition. In modern times it is still associated with substantial morbidity and mortality. ${ }^{1}$ In Denmark, contemporary

\footnotetext{
From the a Department of General and Thoracic Surgery, Städtisches Klinikum

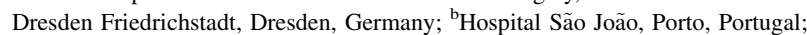
${ }^{\mathrm{c}}$ Szent István University, Budapest, Hungary; ${ }^{\mathrm{d} U n i v e r s i t y ~ H o s p i t a l ~ S t ~ G e o r g e, ~}$ Medical University of Plovdiv, Plovdiv, Bulgaria; ${ }^{\mathrm{e}}$ Hospital Universitario de la Princesa, Madrid, Spain; ${ }^{\mathrm{f}}$ Royal Victoria Hospital, Belfast, United Kingdom; ${ }^{g}$ Klinikum Nuremberg, Nuremberg, Germany; ${ }^{h}$ Salzburger Landeskrankenhaus, Paracelsus Medical University, Salzburg, Austria; ${ }^{\mathrm{i}}$ The University of Hong Kong, Hong Kong, Hong Kong; ${ }^{j}$ St Sophia University Hospital for Pulmonary Diseases, Medical University, Sofia, Bulgaria; and ${ }^{k}$ Klinikum Neumarkt, Neumarkt in der Oberpfalz, Germany.
}

population-based data reveal an overall national mortality rate of $21 \%$ for patients with esophageal perforation, including spontaneous rupture and iatrogenic perforation. ${ }^{2}$
Read at the 95th Annual Meeting of The American Association for Thoracic Surgery, Seattle, Washington, April 25-29, 2015.

Received for publication Feb 19, 2015; revisions received Nov 4, 2015; accepted for publication Nov 30, 2015; available ahead of print Feb 18, 2016.

Address for reprints: Michael Schweigert, MD, PhD, Department of General and Thoracic Surgery, Städtisches Klinikum Dresden Friedrichstadt, Friedrichstr 41, 01067 Dresden, Germany (E-mail: Schweigert-Mi@khdf.de). $0022-5223 / \$ 36.00$

Copyright $(\subset 2016$ by The American Association for Thoracic Surgery http://dx.doi.org/10.1016/j.jtcvs.2015.11.055 


\section{Abbreviation and Acronym \\ $\mathrm{PSS}=$ perforation severity score}

Scanning this QR code will take you to the article title page. To view the AATS 2015 Webcast, see the URL at the end of the article.

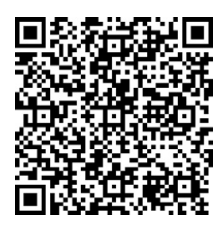

Specialist centers of foregut surgery report comparable results. ${ }^{3}$

The proper management of the condition remains controversial and is influenced by a multitude of factors such as preexisting esophageal pathology, etiology, interval between rupture and diagnosis, clinical condition at presentation, experience of the surgeon, and availability of endoscopic measures. No generally accepted approach for the management of esophageal perforation has been established. Because esophageal rupture is a situation in which straight action without further loss of time is crucial to avoid fatal outcome, a useful tool for decision making would be of great help.

Therefore, the group from the University of Pittsburgh suggested an esophageal perforation severity scoring system based on clinical factors at the time of presentation. ${ }^{4}$ The perforation severity score (PSS) is designed to measure the seriousness of esophageal disruption by weighting clinical variables, which are possible indicators of injury severity and patient outcome. ${ }^{4}$ As a result, the score could be helpful when choosing the operative approach. Furthermore, the Pittsburgh scoring system may serve to identify patients suitable for nonoperative treatment.

The score was established based on experience with 119 cases of esophageal disruption treated at the University of Pittsburgh Medical Center. ${ }^{4}$ Despite the promising results of the original series there has been no validation of the score in an independent population; our study is intended to address this void. We hypothesize that the Pittsburgh PSS is a useful tool for decision making in cases of esophageal rupture.

\section{METHODS}

In a retrospective analysis we collected all cases of esophageal perforation, which were encountered at the participating centers starting from the year 1990. Spontaneous rupture of the esophagus (Boerhaave syndrome), iatrogenic (instrumentation) perforation, as well as traumatic perforation were included, whereas esophageal disruptions caused by thoracic or abdominal surgical procedures were excluded. For the same reason esophageal anastomotic leaks following esophagectomy were also strictly kept out. We believe that these intra- or postoperative complications of surgery are not comparable with the condition generally described as esophageal perforation and require different treatment strategies.

A total of 11 centers of esophageal surgery from 7 countries in Europe and Asia took part in the study: Städtisches Klinikum Dresden Friedrichstadt (Dresden, Germany), Klinikum Nuremberg (Nuremberg, Germany), Klinikum Neumarkt (Neumarkt i.d.OPf., Germany), Salzburger Landeskrankenhaus (Paracelsus Medical University, Salzburg, Austria), Royal Victoria Hospital (Belfast, Northern Ireland, United Kingdom), Hospital Universitario La Princessa (Madrid, Spain), Hospital São João (University of Porto, Portugal), the University of Hong Kong (Hong Kong), Hospital St George (Medical University of Plovdiv, Bulgaria), St Sophia University Hospital for Pulmonary Diseases (Medical University, Sofia, Bulgaria), and the University of Stara Zagora (Stara Zagora, Bulgaria).

Only patients treated after 1990 were included because of the introduction or increased use of endoscopic therapies and shift in treatment paradigms during the past few decades. Local ethics committees approved the study and the need for written consent was waived because of the retrospective study design.

\section{The PSS}

The PSS is a clinical score based on preexisting esophageal pathology and clinical findings at the time of presentation. ${ }^{4}$ All variables are assigned points (range, 1-3) for a possible total score of 18. Points are given to each variable according to the following scale: $1=$ age $>75$ years, tachycardia $(>100 \mathrm{bpm})$, leukocytosis $(>10,000$ white blood cells $/ \mathrm{mL}$ ), or pleural effusion (on chest radiograph, computed tomography, or barium swallow); $2=$ fever $\left(>38.5^{\circ} \mathrm{C}\right.$ ), noncontained leak (on barium swallow or computed tomography), respiratory compromise (respiratory rate $>30$, increasing oxygen requirement, or need of mechanical ventilation), or time to diagnosis $>24$ hours; and $3=$ presence of cancer or hypotension. ${ }^{4}$

\section{Data Collection}

A standardized form was used to collect data uniformly and completely at all participating institutions. The medical records of all patients with esophageal perforation were reviewed and the required information, including all variables needed to calculate the PSS, were filled into the standardized form for further statistical analysis. The following information regarding initial presentation, treatment, clinical course, and outcome were collected: gender, age, etiology of perforation (spontaneous, iatrogenic, or traumatic), preexisting esophageal pathology, site of perforation (cervical, intrathoracic, or abdominal), time to diagnosis, type of management (operative vs nonoperative), type of surgery (primary repair, repair of drain, exclusion, esophagectomy, drainage only, or other procedures), minimally invasive surgical approach, endoscopic stent insertion, need for surgery following initial nonoperative management, morbidity (pleural empyema, mediastinitis, pneumonia, sepsis, acute renal failure, leakage of the repair, or other complications), mortality, length of stay, and the variables of the PSS.

Spontaneous rupture meant Boerhaave syndrome, ${ }^{5}$ whereas iatrogenic rupture was defined as perforation of the esophagus caused by diagnostic or therapeutic instrumentation of the esophagus; for example, flexible or rigid esophagoscopy, interventional endoscopy (balloon dilatation, stent insertion, or percutaneous endoscopic gastrostomy placement), endosonography, transesophageal echocardiography, or placement of a nasogastric tube. Traumatic rupture was defined as esophageal injury caused by external physical force (eg, transportation accidents or chest trauma). This included perforation due to esophageal foreign body ingestion.

Operative management meant any kind of surgical intervention as primary treatment. Nonoperative management comprised all nonsurgical approaches ranging from simple conservative treatment to advanced interventional and endoscopic measures such as stent insertion and image-guided drainage placement.

Preexisting esophageal pathology meant that an esophageal disorder was already known at the time of esophageal perforation. Morbidity was 
TABLE 1. Patient characteristics stratified by the Pittsburgh perforation severity score (PSS)

\begin{tabular}{|c|c|c|c|c|}
\hline Characteristic & Total study population & $\begin{array}{l}\text { Group 1 } \\
\text { PSS } \leq 2\end{array}$ & $\begin{array}{l}\text { Group 2 } \\
\text { PSS 3-5 }\end{array}$ & $\begin{array}{l}\text { Group 3 } \\
\text { PSS }>5\end{array}$ \\
\hline Total number & 288 & 63 & 86 & 120 \\
\hline Male & 173 & 41 & 46 & 86 \\
\hline Female & 96 & 22 & 40 & 34 \\
\hline Age (y) & $61(24.25)$ & $57(23)$ & $66.5(23)$ & $63(21)$ \\
\hline Age $>75 y$ & $62(21.5)$ & $10(15.9)$ & $27(31.4)$ & $22(18.3)$ \\
\hline Etiology: Spontaneous perforation & $119(41.3)$ & $16(25.4)$ & $30(34.9)$ & $65(54.2)$ \\
\hline Etiology: Traumatic perforation & $83(29)$ & $26(41.3)$ & $28(32.5)$ & $24(20.0)$ \\
\hline Etiology: Iatrogenic perforation & $85(29.5)$ & $21(33.3)$ & $28(32.5)$ & $31(25.8)$ \\
\hline Esophageal pathology: No prior pathology & $198(68.8)$ & $53(84.1)$ & $62(72.1)$ & $72(60)$ \\
\hline Esophageal pathology: Cancer & $43(14.9)$ & 0 & $10(11.6)$ & $30(25)$ \\
\hline Esophageal pathology: Stricture & $23(8)$ & $6(9.5)$ & $3(3.5)$ & $10(8.3)$ \\
\hline Esophageal pathology: Diverticulum & $4(1.4)$ & $1(1.6)$ & $1(1.2)$ & $2(1.7)$ \\
\hline Site of perforation: Cervical & $45(15.6)$ & $17(27)$ & $19(22.1)$ & $8(6.7)$ \\
\hline Site of perforation: Thoracic & $202(70.2)$ & $35(55.6)$ & $53(61.6)$ & $99(82.5)$ \\
\hline Site of perforation: Abdominal & $35(12.2)$ & $8(12.7)$ & $14(16.3)$ & $13(10.8)$ \\
\hline
\end{tabular}

Values are presented as $\mathrm{n}$, median (interquartile range), or $\mathrm{n}(\%) . P S S$, Perforation severity score.

defined as presence of morbid conditions related to esophageal perforation. In contrast to pleural effusion, pleural empyema was defined as presence of 1 or more of the following findings: $\mathrm{pH}<7.2$, lactate dehydrogenase $>1000 \mathrm{IU} / \mathrm{mL}$, positive microbiology, or frank pus in the pleural fluid. The diagnosis of mediastinitis was made in case of radiologic (mediastinal fluid collection or mediastinal abscess formation) and clinical signs typical for mediastinitis. Sepsis was defined in accordance with the generally accepted World Health Organization definition. ${ }^{6,7}$ Acute renal failure meant acute impairment of kidney function requiring hemofiltration or hemodialysis. Due to the long mean length of stay in our study, mortality was reported as in-hospital mortality rather than 30-day mortality.

\section{Statistical Analysis}

The independence of the studied categorical variable pairs was tested by Fisher exact test. In case of dichotomous variable pairs odds ratio was also calculated. Wilcoxon Mann-Whitney rank sum test was used for observational data as length of stay. Logistic regression was used to analyze the relationship between dichotomous outcomes (morbidity, mortality, and operative management) and the PSS as continuous independent variable. The goodness of fit of models were checked by the Hosmer-Lemeshow test. Receiver operating characteristic analysis was performed quantifying by area under the curve the predictive performance of the fitted logistic regression models. Statistical analysis was performed using the $\mathrm{R}$ language and environment ( $R$ Foundation for Statistical Computing, Vienna, Austria).

\section{RESULTS}

The study comprises a total of 288 patients with esophageal perforation (Table 1). Operative management $(\mathrm{n}=200 ; 69.4 \%)$ was more frequent than nonoperative management $(\mathrm{n}=88 ; 30.6 \%)$. Endoscopic stent insertion was performed in 31 patients $(10.8 \%)$. Patients with esophageal cancer (34 out of $43 ; 79.0 \%$ ) and stricture (18 out of $23 ; 78.3 \%$ ) were mainly treated operatively.

The most common type of surgery was primary repair $(\mathrm{n}=83)$ followed by surgical drainage $(\mathrm{n}=38)$. Repair over drain (T-tube), esophageal exclusion, and esophagectomy were performed in 21,28 , and 26 patients, respectively. A minimally invasive approach was chosen in only 3 cases. Initial nonoperative management failed in 36 out of 88 patients $(40.9 \%)$ and surgical intervention was required. The most frequent operative procedure after failed initial nonoperative treatment was surgical drainage $(\mathrm{n}=14)$. Primary repair was still feasible in 5 cases, whereas esophagectomy was unavoidable in 8 patients after failed nonoperative management. Repair over drain $(\mathrm{n}=1)$ and esophageal exclusion were less common. Fatal outcome occurred in 8 out of these 36 cases $(22.2 \%)$.

Perforation-related morbidity was encountered in 180 patients $(65.3 \%)$. The most common morbid conditions were sepsis $(\mathrm{n}=61 ; 21.2 \%)$ and pneumonia $(\mathrm{n}=56$; $19.4 \%$ ). Pleural empyema, mediastinitis, leak of the esophageal repair, and acute renal failure were found in $37(12.8 \%), 44(15.3 \%), 18(6.3 \%)$, and $12(4.2 \%)$ patients, respectively. The overall in-hospital mortality rate was $19.8 \%$ (57 out of 288). The median length of stay was 27 days (interquartile range [IQR], 34 days).

\section{PSS}

The distribution of the PSS variables in our study population is displayed in Table 2. The median PSS was 5 (IQR, 6) (Figure 1). Patients with fatal outcome had a significantly higher median PSS than survivors (11 [IQR, 5] vs 1 [IQR, 5]; $P<.001)$. Furthermore, the median PSS was significantly higher in operatively managed cases compared with nonoperative cases (5 [IQR, 6.25] vs 4 [IQR, 6]; $P=.0001$ ).

We used logistic regression to analyze the PSS as a continuous variable for each of the following dichotomized outcomes: leak-associated morbidity, mortality, operative management, and surgery following initial nonoperative management (Table 3). The length of stay was not included 
TABLE 2. Variables of the Pittsburgh perforation severity score (PSS)

\begin{tabular}{|c|c|c|c|c|c|c|}
\hline Variable & Weight (score) & Yes & No & $\begin{array}{c}\text { Group 1 } \\
(\text { PSS } \leq 2 ; \mathbf{n}=63) \\
\text { Yes }\end{array}$ & $\begin{array}{c}\text { Group } 2 \\
(\text { PSS 2-5; } \mathbf{n}=\mathbf{8 6}) \\
\text { Yes }\end{array}$ & $\begin{array}{c}\text { Group } 3 \\
(\text { PSS }>5 ; \mathbf{n}=\mathbf{1 2 0}) \\
\text { Yes }\end{array}$ \\
\hline Age $>75 y$ & 1 & 59 (21.9) & $210(78.1)$ & $10(15.8)$ & $27(31.4)$ & $22(18.3)$ \\
\hline Tachycardia & 1 & 93 (34.6) & $176(65.4)$ & $1(1.6)$ & $13(15.1)$ & $79(65.8)$ \\
\hline Leukocytosis & 1 & $163(60.6)$ & $106(39.4)$ & $23(36.5)$ & $45(52.3)$ & 95 (79.2) \\
\hline Pleural effusion & 1 & $155(57.6)$ & $114(42.4)$ & $7(11.1)$ & $43(50)$ & $105(87.5)$ \\
\hline Fever $>38.5^{\circ} \mathrm{C}$ & 2 & $63(23.4)$ & $206(76.6)$ & $1(1.6)$ & $7(8.1)$ & $55(45.8)$ \\
\hline Noncontained leak & 2 & $140(52.0)$ & $129(48.0)$ & $4(6.3)$ & $39(45.3)$ & $97(80.8)$ \\
\hline Respiratory compromise & 2 & $100(37.1)$ & $169(62.9)$ & $1(1.6)$ & $16(18.6)$ & $83(69.2)$ \\
\hline Timing $>24 \mathrm{~h}$ & 2 & $104(38.7)$ & $165(61.3)$ & $8(12.7)$ & $29(33.7)$ & $67(55.8)$ \\
\hline Hypotension & 3 & $54(20.0)$ & $215(80.0)$ & 0 & $3(3.5)$ & $51(42.5)$ \\
\hline Cancer & 3 & $40(14.9)$ & $229(85.1)$ & 0 & $10(11.6)$ & $30(25)$ \\
\hline
\end{tabular}

Values are presented as score or $\mathrm{n}(\%)$. PSS, Perforation severity score.

because there was no threshold to dichotomize this variable. The analyses showed that the score worked well for predicting morbidity (area under the curve, 0.77) and mortality (area under the curve, 0.83) (Table 3). Prediction for the need of operative management was not as good as for the other variables (area under the curve, 0.65). However, it must be understood that the score was retrospectively calculated and the decision for operation was not based on the score. Table 3 summarizes the results of the logistic regression analysis, including the increase in odds ratio (OR) for each dependent variable by increasing the PSS by 1 unit.

\section{Stratification Based on the Pittsburgh PSS}

In Pittsburgh no survivors with a score of 9 or more were observed. To test this finding we divided our study population in the middle of the possible score range

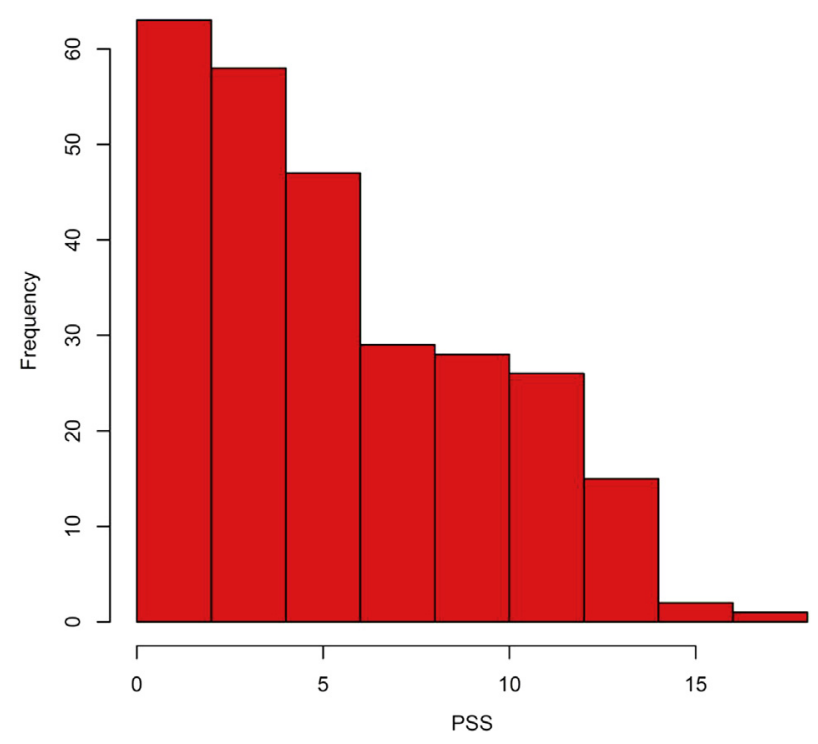

FIGURE 1. Distribution of perforation severity score (PSS). The distribution of the PSS within the study population is shown.
(PSS $<9$ vs PSS $\geq 9$ ) and looked at the outcome. There were 196 cases with PSS $<9$ and 72 with PSS $\geq 9$. Patients with PSS $\geq 9$ had 9 times higher odds for fatal outcome than patients with PSS $<9$ (35 out of 72 vs 18 out of 196; OR, $9.25 ; 95 \%$ confidence interval [CI], 4.55-19.39; $P<.001)$. In contrast to the results from Pittsburgh we had several survivors with PSS $\geq 9$ in our study. According to the area under the curve analysis (c-statistic) PSS $=7$ was the cutoff for mortality in our series (area under the curve, 0.761). Patients with PSS $\geq 7$ were 10 times more likely to die (OR, 10.23; 95\% CI, 4.79-23.59; $P<.001)$.

In accordance with the original publication we divided the study population into 3 groups (group 1: PSS $\leq 2$, group 2: PSS $=3-5$, and group 3: PSS $>5$ ). ${ }^{4}$ There were 63 patients in group $1(23.4 \%), 86$ in group $2(32 \%)$, and 120 in group $3(44.6 \%)$ (Table 1). Statistically significant association between the groups and the occurrence of perforation-related morbidity was seen (Table 4 ). For group 2 the odds of morbidity (presence of 1 or more perforation-related morbid conditions) were nearly 3 times higher than in group $1(\mathrm{OR}, 2.76$; 95\% CI, 1.33-5.85; $P=.004)$. Patients belonging to group 3 had 10 times higher odds for perforation-related morbidity compared with group 1 (OR, 10.22; 95\% CI, 4.79-22.72; $P<.0001)$. No significant difference was observed between group 2 and 3 .

Close relation between group affiliation and mortality rate was also visible. Although the difference was not statistically significant (OR, 2.27; 95\% CI, 0.39-23.82; $P=.468$ ) between group 1 (PSS $\leq 2$ ) and group 2 (PSS, 3-5), we observed a significant difference comparing group 1 to group 3 (PSS $>5$ ). The odds of mortality were 18 times higher for group 3 (OR, 18.33; 95\% CI, 4.47-162.07; $P<.00001)$. In addition, patients belonging to group 3 had also significantly higher mortality compared with group 2 (OR, 8.03; 95\% CI, 3.17-24.41; $P<.0001)$. 
TABLE 3. Predictive performance of the fitted logistic regression models using perforation severity score as the continuous variable

\begin{tabular}{|c|c|c|c|c|c|c|c|c|}
\hline \multirow[b]{2}{*}{ Dichotomized variable } & \multirow{2}{*}{$\begin{array}{c}\text { Odds ratio } \\
\text { (95\% confidence } \\
\text { interval) }\end{array}$} & \multirow{2}{*}{$\begin{array}{c}\text { Area under the } \\
\text { receiver-operator-curve/ } \\
\text { c-statistic }(95 \% \\
\text { confidence interval) }\end{array}$} & \multirow{2}{*}{$\begin{array}{c}\text { Positive } \\
\text { predictive } \\
\text { value }(\%) \\
\end{array}$} & \multirow{2}{*}{$\begin{array}{l}\text { Negative } \\
\text { predictive } \\
\text { value }(\%)\end{array}$} & \multirow[b]{2}{*}{$\begin{array}{c}\text { Accuracy } \\
(\%)\end{array}$} & \multicolumn{3}{|c|}{ Hosmer-Lemeshow } \\
\hline & & & & & & $\chi^{2}$ & df & $\begin{array}{c}P \\
\text { value }\end{array}$ \\
\hline Morbidity & $1.34(1.23-1.47)$ & $0.77(0.71-0.83)$ & 75 & 64 & 72 & 4.5 & 8 & .807 \\
\hline Mortality & $1.41(1.28-1.55)$ & $0.83(0.76-0.89)$ & 68 & 86 & 84 & 10.1 & 8 & .256 \\
\hline Operative management & $1.15(1.07-1.24)$ & $0.65(0.58-0.72)$ & 70 & - & 70 & 19.8 & 8 & .011 \\
\hline $\begin{array}{l}\text { Surgery following nonoperative } \\
\text { management }\end{array}$ & $1.05(0.96-1.15)$ & $0.57(0.46-0.68)$ & - & 75 & 75 & 8.0 & 8 & .438 \\
\hline
\end{tabular}

The frequency of operative management was associated with the groups, too. In patients with high PSS operative management was significantly more common than in cases with PSS $\leq 2$ (group 1). Comparing group 2 with group 1 we found 3 times higher odds for operative management (65 out of 86 vs 31 out of 63 ; OR, $3.17 ; 95 \%$ CI, $1.50-6.82 ; P=.001)$. A similar association was seen comparing group 3 to group 1 ( 92 out of 120 vs 31 out of 63; OR, 3.37; 95\% CI, 1.68-6.84; $P=.00025$ ), whereas no significant difference was detectable between group 3 and group 2 (92 out of 120 vs 65 out of 86; OR, 1.06; $95 \%$ CI, 0.52-2.13; $P=.87$ ). Not only the general frequency of operative management differed between the groups but also the extent of the necessary surgical procedures. The frequency of esophagectomy clearly depended on the group affiliation. The rate of esophagectomy was 0 out of 63,9 out of 86 , and 17 out of 120 for the 3 groups, respectively. The differences were significant between group 1 and the other groups $(P=.013$ and $P=.003)$ but not between group 2 and 3 (OR, 1.32; 95\% CI, 0.52-3.58; $P=.67$ ).

TABLE 4. Morbidity and management by Pittsburgh perforation severity score (PSS) strata

\begin{tabular}{|c|c|c|c|}
\hline & $\begin{array}{c}\text { Group } 1 \\
(\mathrm{PSS} \leq 2)\end{array}$ & $\begin{array}{c}\text { Group 2 } \\
(\mathrm{PSS}=\mathbf{3 - 5})\end{array}$ & $\begin{array}{c}\text { Group } 3 \\
(\text { PSS }>5)\end{array}$ \\
\hline $\mathrm{N}$ & 63 & 86 & 120 \\
\hline \multicolumn{4}{|l|}{ Morbidity } \\
\hline Overall morbidity & $20(31.7)$ & $49(57)$ & $99(82.5)$ \\
\hline Pleural empyema & $1(1.6)$ & $7(8.1)$ & $28(23.3)$ \\
\hline Mediastinitis & $7(11.1)$ & $5(5.8)$ & $32(26.7)$ \\
\hline Pneumonia & $4(6.3)$ & $14(16.3)$ & $37(30.8)$ \\
\hline Sepsis & $4(6.3)$ & $13(15.1)$ & $44(36.7)$ \\
\hline \multicolumn{4}{|c|}{ Management and outcome } \\
\hline Length of stay (d) & $15(12)$ & $30.5(30.25)$ & $38(38)$ \\
\hline Esophagectomy & $0(0)$ & $9(10.5)$ & 17 (14.2) \\
\hline $\begin{array}{l}\text { Initial non-operative } \\
\text { management }\end{array}$ & $32(50.8)$ & $21(24.4)$ & $28(23.3)$ \\
\hline $\begin{array}{l}\text { Surgery after failed } \\
\text { nonoperative } \\
\text { management }\end{array}$ & $6 / 32(18.8)$ & $6 / 21(28.6)$ & $20 / 28(71.4)$ \\
\hline Mortality & $2(3.2)$ & $6(7)$ & $45(37.5)$ \\
\hline
\end{tabular}

The median length of stay was 15 (IQR, 12) days for group 1, 30.5 (IQR, 30.25) days for group 2, and 38 (IQR, 38 ) days for group 3 (Table 2). The differences between group 1 and the other groups were significant $(P<.0001)$, whereas the difference between group 2 and group 3 was not significant $(P=.27)$.

\section{Operative versus Nonoperative Management}

We compared characteristics and outcome of patients receiving operative management $(n=200)$ with patients with nonoperative treatment $(\mathrm{n}=88)$ (Table 5). No significant difference in the rate of perforation related morbidity was found (48 out of 88 vs 130 out of 200; OR, $0.65 ; 95 \% \mathrm{CI}, 0.38-1.13 ; P=.11)$. The patients undergoing surgery had a significantly longer median length of stay (31 [IQR, 38] days vs 21.5 [IQR, 30] days; $P=.003)$. Although

TABLE 5. Nonoperative versus operative patients

\begin{tabular}{|c|c|c|c|}
\hline Variable & $\begin{array}{c}\text { Nonoperative } \\
\text { patients }\end{array}$ & $\begin{array}{c}\text { Operative } \\
\text { patients }\end{array}$ & $\begin{array}{c}P \\
\text { value }\end{array}$ \\
\hline $\mathrm{N}$ & 88 & 200 & \\
\hline Age (y) & $62(24.5)$ & $60.5(23.5)$ & .77 \\
\hline \multicolumn{4}{|l|}{ Etiology } \\
\hline Spontaneous & 37 & 82 & .3 \\
\hline Iatrogenic & 21 & 64 & \\
\hline Traumatic/foreign body & 30 & 54 & \\
\hline \multicolumn{4}{|l|}{ Site of perforation } \\
\hline Cervical & 13 & 32 & .91 \\
\hline Thoracic & 61 & 141 & \\
\hline Abdominal & 9 & 26 & \\
\hline \multicolumn{4}{|l|}{ Outcome } \\
\hline Length of stay (d) & $21.5(30)$ & $31(38)$ & .003 \\
\hline Morbidity & 48 & 130 & .11 \\
\hline Mortality & 13 & 44 & .2 \\
\hline Perforation severity score & $4.40 \pm 3.66$ & $6.44 \pm 4.00$ & $<.001$ \\
\hline Perforation severity score & $4(6)$ & $5(6.25)$ & $<.001$ \\
\hline $\begin{array}{l}\text { Group } 1 \text { perforation } \\
\text { severity score }\end{array}$ & 32 & 31 & \\
\hline $\begin{array}{l}\text { Group } 2 \text { perforation } \\
\text { severity score }\end{array}$ & 21 & 65 & \\
\hline $\begin{array}{l}\text { Group } 3 \text { perforation } \\
\text { severity score }\end{array}$ & 28 & 92 & .0004 \\
\hline
\end{tabular}


TABLE 6. Early versus late patient outcomes

\begin{tabular}{lccc}
\hline \multicolumn{1}{c}{ Variable } & $\mathbf{1 9 9 0 - 2 0 0 4}$ & $\mathbf{2 0 0 5 - 2 0 1 4}$ & $\boldsymbol{P}$ value \\
\hline $\mathrm{N}$ & 126 & 161 & \\
Age $(\mathrm{y})$ & $57.7 \pm 18.29$ & $61.61 \pm 17.66$ & .7657 \\
Perforation severity score & $5(7)$ & $5(5)$ & .3402 \\
Time $>$ 24 h & $43(34.1)$ & $63(39.1)$ & .54 \\
Operative management & $102(81.0)$ & $97(60.2)$ & $<.001$ \\
Nonoperative management & $24(19.0)$ & $64(39.8)$ & $<.001$ \\
Stent & $3(2.4)$ & $28(17.4)$ & $<.001$ \\
Morbidity & $68(54.0)$ & $109(67.7)$ & .02 \\
Mortality & $24(19.0)$ & $32(19.9)$ & .88 \\
\hline
\end{tabular}

Values are presented as $n$, mean \pm standard deviation, median (interquartile range), or $\mathrm{n}(\%)$.

the mortality rate was lower in the nonoperative group the difference was not statistically significant (OR, 0.61; 95\% CI, 0.28-1.24; $P=.20$ ).

\section{Early versus Late Patients}

Because treatment for esophageal perforation has evolved over time we divided our series into 2 time periods (1990-2004 and 2005-2014) and compared demographic data, management, and outcome (Table 6). Early patients had a significantly higher rate of operative treatment (102 out of 126 vs 97 out of 161; OR, 2.79; 95\% CI, 1.58-5.06; $P<.001)$. In contrast, stent implantation was significantly more common in the late group (3 out of 126 vs 28 out of 161; OR, 0.13; 95\% CI, 0.02-0.43; $P<.001)$. Mortality did not change significantly over time (24 out of 126 vs 32 out of 161 ; OR, 0.94 ; $95 \% \mathrm{CI}$, $0.50-1.77 ; P=.88)$.

\section{Site of Perforation}

To analyze the influence of the site of perforation on management and outcome we formed 3 groups (cervical, thoracic, and abdominal) (Table 6). Neither in the distribution of PSS nor in the type of management any statistically significant differences were recognized between the groups. There was a trend for increasing mortality from neck to abdomen with cervical perforations having the lowest and abdominal perforations having the highest mortality rate. However, only the difference

TABLE 7. Site of perforation

\begin{tabular}{lccc}
\hline & \multicolumn{3}{c}{ Site of perforation } \\
\cline { 2 - 4 } \multicolumn{1}{c}{ Variable } & Cervical & Thoracic & Abdominal \\
\hline Number & 45 & 202 & 35 \\
Perforation severity score & $3.5(3)$ & $6(5.5)$ & $5(5)$ \\
Perforation severity score range & $0-15$ & $0-17$ & $0-14$ \\
Nonoperative management & $13(28.9)$ & $61(30.2)$ & $9(25.7)$ \\
Operative management & $32(71.1)$ & $141(69.8)$ & $26(74.3)$ \\
Mortality & $4(8.9)$ & $42(20.8)$ & $11(31.4)$ \\
\hline
\end{tabular}

Values are presented as median (interquartile range), range, or $\mathrm{n}(\%)$. between cervical and abdominal site was significant (4 out of 45 vs 11 out of 35 ; OR, 0.22 ; 95\% CI, 0.05-0.83; $P=.02$ ) (Table 7).

\section{DISCUSSION}

Esophageal perforation is an emergency situation that requires quick decision making to save the patient. ${ }^{1-4} \mathrm{~A}$ multitude of operative strategies have been suggested to deal with esophageal disruption. ${ }^{8-15}$ In recent years interventional endoscopy and radiology have further broadened the spectrum of available treatment options. ${ }^{5}$ Modern nonoperative management ranges from conservative treatment to advanced interventional procedures. ${ }^{16-19}$

Against this background the group from Pittsburgh suggested a perforation severity scoring system. ${ }^{4}$ Our study aim was to determine whether the PSS can be used to stratify patients with esophageal perforation into distinct subgroups with differential morbidity and mortality outcomes. Furthermore we looked at whether the PSS strata could be used to identify candidates for nonoperative management.

The overall mortality rate in our series was $19.8 \%$. This result is in accordance with other contemporary reports ${ }^{1-3}$ and comparable with the $14.2 \%$ mortality in the study from Pittsburgh. ${ }^{4}$ Furthermore, the rates of perforation related morbidity were practically the same in both series. As a consequence, we may assume that our results are not impaired by excessive perforation-related morbidity and mortality.

Our results clearly demonstrate that the PSS reliably measures the seriousness of esophageal perforation. Morbidity, frequency of operative treatment, length of stay, and mortality were strongly associated with the score value. Stratification was performed by creating low(PSS $\leq 2$ ), intermediate- (PSS = 3-5), and high-risk (PSS $>5$ ) groups. The low-risk group had significantly better outcomes regarding morbidity, mortality, and length of stay compared with the other groups. Moreover, frequency as well as dimension of operative treatment was significantly lower. These observations lead to conclude that affiliation to group 1 (low PSS) is associated with more favorable outcome and might be an indicator for possible nonoperative treatment. The fact that each of the most threatening variables, esophageal cancer and circulatory shock, is associated with 3 points and therefore by definition excluded from group 1 , adds further support to this conclusion.

The intermediate group (PSS $=3-5$ ) showed no statistically significant differences in treatment, length of stay, or perforation-related morbidity compared with the high-risk group. Even the frequency of esophagectomy was similar. However, the mortality rate was significantly lower than in the high PSS group. Therefore, we may conclude that belonging to the intermediate PSS group is 


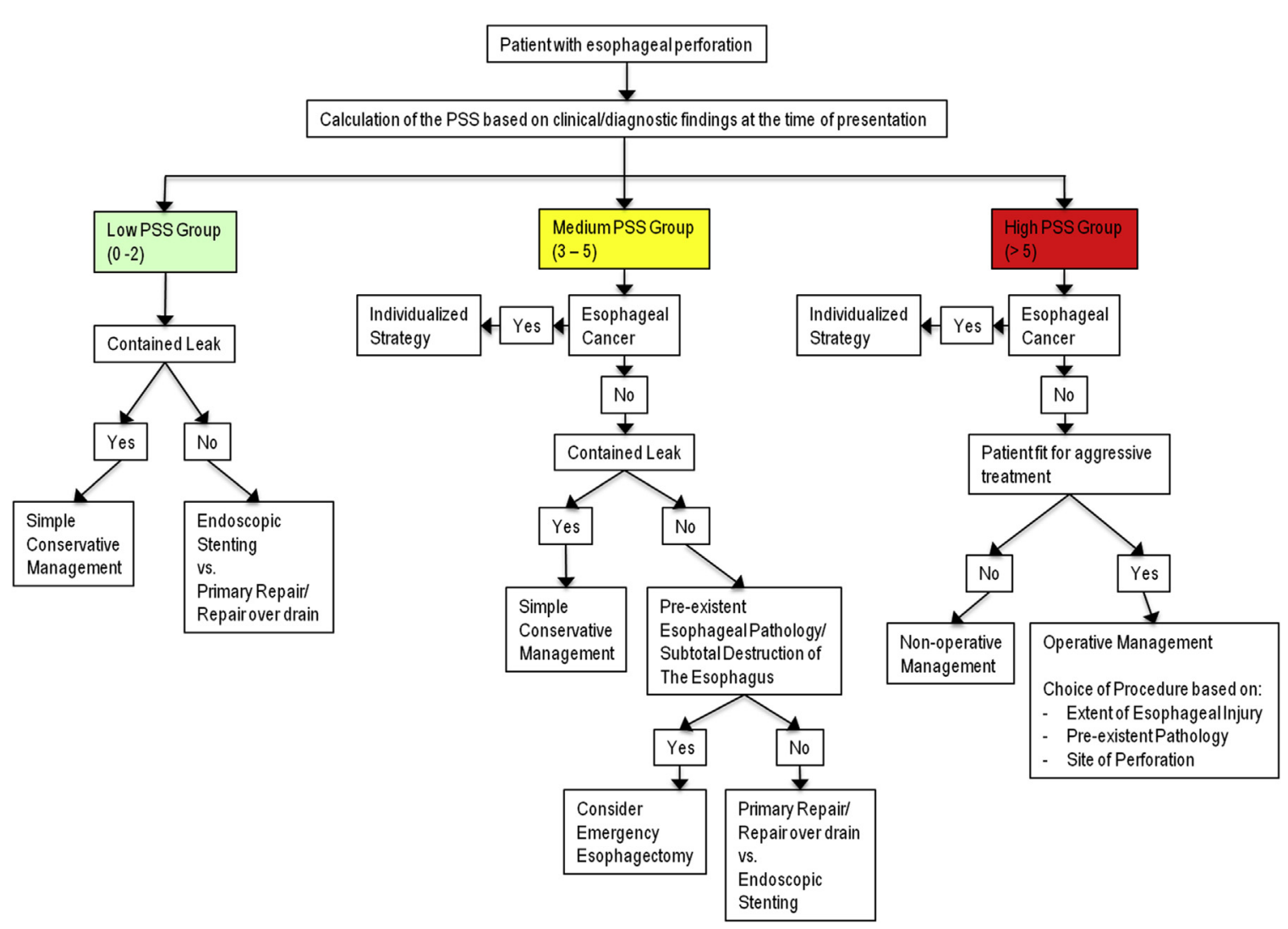

FIGURE 2. The decision tree shows our general suggestions for the management of esophageal perforation based on the Pittsburgh perforation severity score (PSS) and the results of our study. In group 1 (low PSS) the focus is on nonoperative management. In case of a contained leak simple conservative management is suggested, whereas in cases of noncontained esophageal perforation endoscopic stenting should be considered. Alternatively primary surgical repair or repair over drain might be performed. In group 2 (medium PSS) patients with noncontained leak should preferably be managed by surgical intervention and endoscopic stenting is only suggested as second choice. In case of contained perforation, simple conservative management seems to be justified. Group 3 (high PSS) is associated with the worst outcome. Therefore, aggressive treatment should be considered in all reasonable cases. Perforated esophageal cancer requires individualized treatment strategies based on cancer staging, previous treatment, comorbidity, and performance status.

associated with a more favorable prognosis compared with group 3. As a result of our analysis, we suggest a decision tree for the management of esophageal perforation based on the Pittsburgh PSS (Figure 2).

The high-risk group (PSS, >5) had the worst prognosis and the most substantial mortality. Odds for mortality were 8 times higher compared with the intermediate group and 18 times higher compared with the low-risk group. The mortality rate reached $37.5 \%$. Because these patients are most endangered by esophageal perforation, early and aggressive treatment is mandatory to avoid fatal outcome (Figure 2).

Because this is the first study validating the PSS, we believe that the original grouping should be maintained to report the results of the risk stratification. Restructuring of the risk groups should be reserved to further studies and be based on our experience with the original groups. In Pittsburgh no survival was observed above a score value of 9. The area under the curve analysis showed PSS $=7$ as the cutoff in our series. Patients with
PSS $\geq 7$ were 10 times more likely to die (OR, 10.23; 95\% CI, 4.79-23.59; $P<.001)$. Therefore, the existing groupings (PSS $\leq 2$, PSS $=3-5$, and PSS $>5$ ) could be extended by a fourth group (PSS $\geq 7$ ). Furthermore, the intermediate group could be redefined to achieve better separation between the intermediate- and the high-risk groups.

Site of perforation could be included into the score, too. Cervical perforation is associated with significantly lower mortality compared with thoracic or abdominal rupture. Therefore, inclusion of the site of perforation into the score would probably lead to better risk stratification. Alternatively, the existing scoring system could be interpreted in different ways in cervical and interthoracic/abdominal perforations. Further studies are required to determine whether expansion of the sore by formation of a fourth group (ie, PSS $\geq 7$ ) or by new variables such as site of perforation might be beneficial for risk stratification.

The main limitation of our study is that it is a retrospective analysis of data in which the Pittsburgh PSS was not 
used in treatment allocation. Prospective studies would be extremely helpful to test the usefulness of the scoring system. As esophageal perforation is a rare condition, so prospective studies are not easy to realize. Creation of a multi-institutional database could be the solution.

Creation of such a database is our next step and requires the cooperation of more expert centers. Because our current results demonstrated that the PSS is able to categorize patients, we believe that suggesting a decision tree for the management of esophageal perforation based on the Pittsburgh PSS is justified (Figure 2). Validation of the suggested decision tree would also be part of further studies; for example, analysis of the above-mentioned prospectively collected database. One good example for such a strategy is the development of a predictive score for bronchopleural fistula by using the French national database Epithor. ${ }^{20}$

In our series nonoperative management was not associated with higher mortality or more unfavorable outcome regarding perforation-related morbidity or lengths of stay. However, nonoperative treatment was only successful in $60 \%$ of cases. In the end 36 out of 88 patients underwent surgery and 8 underwent esophagectomy. From these results we can draw the conclusion that better selection criteria for nonoperative management are urgently required. At this point the Pittsburgh perforation severity scoring system could be helpful.

\section{CONCLUSIONS}

The Pittsburgh PSS is associated with the seriousness of esophageal perforation. The score is helpful to assess the severity and potential consequences of esophageal injury and stratifies patients into low-, intermediate-, and high-risk groups with differential morbidity and mortality outcomes. Prospective studies are required to analyze the influence of the Pittsburgh scoring system on the treatment of esophageal perforation. Based on the PSS strata a decision tree was suggested (Figure 2).

\section{Conflict of Interest Statement}

Authors have nothing to disclose with regard to commercial support.

You can watch a Webcast of this AATS meeting presentation by going to: http://webcast.aats.org/2015/Video/ Tuesday/04-28-15_6C_1500_Schweigert.mp4.

\section{References}

1. Søreide JA, Konradsson A, Sandvik OM, Øvrebø K, Viste A. Esophageal perforation: clinical patterns and outcomes from a patient cohort of Western Norway. Dig Surg. 2012;29:494-502.

2. Ryom P, Ravn JB, Penninga L, Schmidt S, Iversen MG, Skov-Olsen P, et al. Aetiology, treatment and mortality after oesophageal perforation in Denmark. Dan Med Bull. 2011;58:A4267.

3. Wahed S, Dent B, Jones R, Griffin SM. Spectrum of oesophageal perforations and their influence on management. Br J Surg. 2014;101:e156-62.
4. Abbas G, Schuchert MJ, Pettiford BL, Pennathur A, Landreneau J, Landreneau J, et al. Contemporaneous management of esophageal perforation. Surgery. 2009; 146:749-55; discussion 755-6.

5. Schweigert M, Dubecz A, Solymosi N, Ofner D, Stein HJ. Times and trends in the treatment of spontaneous perforation of the esophagus: from Herman Boerhaave to the present age. Am Surg. 2013;79:902-8.

6. Lever A, Mackenzie I. Sepsis: definition, epidemiology, and diagnosis. BMJ. 2007;335:879-83.

7. Bone RC, Balk RA, Cerra FB, Dellinger RP, Fein AM, Knaus WA, et al Definitions for sepsis and organ failure and guidelines for the use of innovative therapies in sepsis. The ACCP/SCCM Consensus Conference Committee American College of Chest Physicians/Society of Critical Care Medicine. Chest. 1992; 101:1644-55.

8. Barrett NR. Report of a case of spontaneous perforation of the oesophagus successfully treated by operation. Br J Surg. 1947;35:216-8.

9. Olsen AM, Clagett OT. Spontaneous rupture of the esophagus; report of a case with immediate diagnosis and successful surgical repair. Postgrad Med. 1947; 2:417-21.

10. Orringer MB, Stirling MC. Esophagectomy for esophageal disruption. Ann Thorac Surg. 1990;49:35-42.

11. Reeder LB, DeFilippi VJ, Ferguson MK. Current results of therapy for esophageal perforation. Am J Surg. 1995;169:615-7.

12. Whyte RI, Iannettoni MD, Orringer MB. Intrathoracic esophageal perforation. The merit of primary repair. J Thorac Cardiovasc Surg. 1995;109:140-4.

13. Bufkin BL, Miller JI Jr, Mansour KA. Esophageal perforation: emphasis on management. Ann Thorac Surg. 1996;61:1447-51.

14. Iannettoni MD, Vlessis AA, Whyte RI, Orringer MB. Functional outcome after surgical treatment of esophageal perforation. Ann Thorac Surg. 1997;64 1606-9.

15. Vallböhmer D, Hölscher AH, Hölscher M, Bludau M, Gutschow C, Stippel D et al. Options in the management of esophageal perforation: analysis over a 12-year period. Dis Esophagus. 2010;23:185-90.

16. Schweigert M, Beattie R, Solymosi N, Booth K, Dubecz A, Muir A, et al. Endoscopic stent insertion versus primary operative management for spontaneous rupture of the esophagus (Boerhaave syndrome): an international study comparing the outcome. Am Surg. 2013;79:634-40.

17. Dasari BV, Neely D, Kennedy A, Spence G, Rice P, Mackle E, et al. The role of esophageal stents in the management of esophageal anastomotic leaks and benign esophageal perforations. Ann Surg. 2014;259:852-60.

18. Kuehn F, Schiffmann L, Rau BM, Klar E. Surgical endoscopic vacuum therapy for anastomotic leakage and perforation of the upper gastrointestinal tract. J Gastrointest Surg. 2012;16:2145-50.

19. Schorsch T, Müller C, Loske G. Endoscopic vacuum therapy of anastomotic leakage and iatrogenic perforation in the esophagus. Surg Endosc. 2013;27: 2040-5.

20. Pforr A, Pagès PB, Baste JM, Thomas P, Falcoz PE, Lepimpec Barthes F, et al. A predictive score for bronchopleural fistula established using the French database Epithor. Ann Thorac Surg. 2016;101:287-93.

Key Words: esophagus, esophageal perforation, foregut surgery, sepsis

\section{Discussion}

Dr Shanda Blackmon (Rochester, Minn). I would like to thank The American Association for Thoracic Surgery and the Program Committee for allowing me to discuss this work and I would like to congratulate Dr Schweigert and his colleagues for their tremendous efforts to accumulate such a large consecutive case series of esophageal perforations in these 11 centers over 24 years.

I have 2 questions and I will ask them sequentially. In your series you state that the initial nonoperative management was not associated with worse outcomes, yet this group included 31 stent and vac patients. You also report a $40 \%$ failure of initial nonoperative management. You do 
not really state whether or not they were in the stent group. I am curious if your study shows that the scoring system predicts management, and if it does, how would it do that? Do you think if we classify patients based on their perforation severity score (PSS) into an algorithm of operative versus nonoperative management that would enhance the success of managing those patients? How long do we wait before we rescore them? As you have shown, initially if you triage a patient into 1 treatment versus another, the esophagectomy or the esophageal repair failed in your series $20 \%$ of the time and patients stayed in the hospital for 40 days. Clearly what was initially done did not work. Should we just assess them and give them a score once or should we give them a score every day in the hospital? As surgeons, we are not very good at looking at patients and saying what we did worked or did not work. We just do something and then we wait.

Dr Schweigert. First of all, I have to repeat that this is a retrospective study and we calculated this score retrospectively, which means that these patients were managed without the score. In our study, as you already mentioned, we had a lot of failure in the nonoperative group. Although there was no higher mortality, we saw that out of 88 patients, finally 36 underwent surgery, and 8 of them underwent esophagectomy. Obviously these patients were very poorly selected, and, in my opinion, our data strongly suggest that with the introduction of this score it might be better to select the proper patients for nonoperative and operative treatment. This score is only meant to be used once, at the initial presentation. We have no data or experience with repeatedly using this score, and I do not believe it makes sense. You have a patient in an emergency department, you know he or she is experiencing an esophageal perforation, and you calculate the score. You have a clinical view of this patient, you see his condition, you have the score value, and this will enable you to make a strong and good decision regarding operative versus nonoperative management, and it might even be helpful to consider which type of nonoperative management.

Dr Blackmon. I just want to emphasize that you do not just assess them 1 time. A patient who may be appropriate for nonoperative management on the first day may need to have surgery or an intervention several days later if that was not a good pathway for them. I think that is going to be something important that we need to look at.

My second question is, you recently published a subgroup of these patients in American Surgeon comparing the stent versus surgery groups and concluded that stenting had a higher risk for fatal outcome. Stenting often does not work alone because people try to stent an undrained leak and they do not check for a seal. The stents erode into structures because they exert radial force against fixed structures. How would you use the PSS system to change the way that we select patients for the type of intervention, not whether they could be managed conservatively or aggressively, but the type? Would you recommend stenting for a PSS of 1 or esophagectomy or diversion for a PSS of 3 ? And why don't we do more belt and suspender treatments? In your series the morbidity and mortality was extremely high. Should we take these patients who clearly are in group 3 and do an internal buttress, endoluminal suturing, or vac and an external decortication with good drainage of the wound and a muscle flap on top? Why don't we do everything all at once?

Dr Schweigert. You mentioned our series where we compared the stent versus the primary operative approach for Boerhaave's syndrome. These were only patients with Boerhaave's syndrome-spontaneous rupture-and we compared roughly 20 cases against each other, 20 stents and 20 operative, and we found that the stents were not very useful. Most of our stented patients finally underwent surgery because of pleural empyema, erosion of the stent, failure to reliably close the leak, or stent migration. I think our enthusiasm for endoscopic stenting, which was there 10 years or 12 years ago, has now diminished considerably. We have seen a lot of side effects of endoscopic stenting, which is true for esophageal perforation as well as for the management of postoperative leaks following esophagectomy with an intrathoracic anastomosis. So there are a lot of side effects and stents may not be very useful for every patient. In our study analysis, stents were inserted by different hospitals, under different conditions, and I do not know if we can now make conclusions with this retrospective series from 11 institutions on the usefulness of stenting. But, in our experience, stenting is not the best option for esophageal perforation and we saw a high failure rate. Probably this score could be used to avoid stenting for patients with a low PSS. A patient with Boerhaave's syndrome who has a PSS of 1, I do not think that this patient needs a stent. The patient can probably be safely managed with a simple conservative management. Stent insertion might be overtreating these patients. You insert the stent with all the risks of a stent and with all the problems of a stent, and these risks are considerably high. We have seen cases of vascular erosions, aortic erosions, and you cannot manage these complications. If you have a patient with Boerhaave's syndrome, which means with an otherwise healthy esophagus, and you have a very low score of 0,1 , or 2 , then you probably can manage this patient conservatively, simple conservative, which means nil by mouth and so on, but not with an endoscopic intervention. And the high endoscopic interventions, like stenting, in our experience, and now I speak from my institution, which is the Klinikum Nuremberg and Dresden, are not better than the traditional operative approaches, for example, primary repair, or if you want to buttress the leak with a muscle 
flap, I think this is an excellent option and is often the better option than stenting, and then you have stent migration, you have to retrieve the stent, insert a new stent, a longer stent, a bigger stent diameter.

Dr Blackmon. That's a little bit bigger answer than I was looking for, but thank you.

Dr Johnathan Spicer (Houston, Tex). I have more of a comment. We just recently presented, about an hour ago, our series of 200 patients with esophageal perforation. I was very intrigued by your study and I think it is a great opportunity to collaborate and amalgamate our databases and move forward with a prospective registry on esophageal perforation so that we can actually test these hypotheses and specific etiologies of esophageal perforation. One of the major criticisms we had is that it is such a heterogeneous population, with heterogeneous treatment approaches, and I believe you alluded to the same issues. By building this large registry, we can actually start looking at individual etiologies and treatment paradigms with large numbers.

Dr Hiran Fernando (Boston, Mass). I think you showed that the score correlated with outcome and that that is important, but in your conclusion you said that for the sickest patients, you should not do stenting. I disagree with that because sometimes the sickest patients are the ones in whom you want to try and avoid an operation. For instance, I don't know what you did for your 98-year-old patient in the series. Stenting and drainage might be a better way to go in sicker patients. I do not think your data show that and I do not think you can conclude that.

Dr Schweigert. The comments were personal comments that were not supported by our data. Our data are on the score, and the prediction of the score was a selection of patients with nonoperative versus operative or the risk stratification of patients with an esophageal perforation with a high score and with a lower score. These comments are personal comments and comments from the experience of my own institution, my own practice, and smaller studies we have done in history, but they are not supported by these data and it was not the aim of this study. Definitely a stent may be a good decision for selected patients. As I told you, 10 years ago we were very enthusiastic about stents, and I remember in a study doing that. The stent would be a means to avoid an operation in the majority of patients, to avoid the hazards of an operation, the risks of an operation, but by introducing the stenting and by stenting probably too many patients who were not ideal candidates for stenting, we introduced risks to our patient series. Personally, I think we should really stratify the patients and we should not simply stent someone who could be managed nonoperatively. There are different managements in nonoperative treatment. You can, for example, just apply a simple conservative treatment for patients who are not very affected by esophageal perforation. If you have a contained leak in an otherwise healthy esophagus, why not just try a simple conservative management? On the other hand, if you have a very old patient and you want to avoid an operation but you have a total destructed organ, then it might be better to start early with an aggressive treatment before this patient develops a septic disease, with septic shock and multiorgan failure, and then probably you will not be able any longer to rescue this patient, but if you initially start with an aggressive treatment, even in older patients who are severely affected by esophageal perforation who have a great esophageal injury, then probably you will receive better results than delaying the proper treatment and then operating on a patient with full sepsis. 